\title{
Measuring Pressure Drop Under Non Ideal Conditions*
}

\author{
by \\ Malcolm Austin \\ CERULEAN, Rockingham Drive, Linford Wood East, Milton Keynes, MK14 6LY, UK
}

\section{SUMMARY}

The method of measurement of the pressure drop (PD) of cigarette filter rods and the draw resistance of cigarettes is defined in ISO 6565-2002 (1). This standard defines the calibration and use of a transfer standard to calibrate the measuring instrument and also defines the measurement procedure for cigarette and filter samples. The procedure described in the standard assumes that the measurement conditions are constant and that the sample is in equilibrium with the measurement environment.

In 2001, the Cooperation Center for Scientific Research Relative to Tobacco (CORESTA) formed a Task Force to investigate the problems associated with the calibration of PD transfer standards that are caused, primarily, by environmental effects. The work of this task force has lead to the harmonisation of the calibration methods between supplier laboratories and to a method for compensation for the effects of atmospheric conditions. These together have considerably reduced the inter-laboratory differences and will eventually lead to a revision of the CORESTA Recommended Method and ISO 6565 Standard.

During the work of this Task Force, it has become evident that further work will be necessary to deal with similar errors encountered during the calibration of PD measurement instruments and during the PD measurement of cigarette and filter rod samples. These errors occur in real measurement situations due to the problems in meeting the ISO 6565 conditions and other necessary requirements. This can give rise to errors in the indicated PD and can considerably degrade the confidence that can be placed in the results.

This paper examines many of the practical problems in the measurement of PD and attempts to estimate the type and magnitude of the errors that might be experienced. [Beitr. Tabakforsch. Int. 22 (2006) 6-12]

\section{ZUSAMMENFASSUNG}

Die Messmethode für den Druckabfall (PD) an Zigarettenfilterstäben und den Zugwiderstand von Zigaretten ist in der ISO-Norm ISO 6565-2002 (1) definiert. Diese Norm legt die Kalibrierung und den Gebrauch von Kalibrierstandards für die Kalibrierung des Messinstrumentes fest. Außerdem wird die Messmethode für Zigaretten- und Filterproben definiert. Für die standardmäßige Anwendung dieser Methode sollen die Messbedingungen konstant und die Probe im Gleichgewicht mit der Messumgebung sein.

2001 bildete die CORESTA (Cooperation Center for Scientific Research Relative to Tobacco) eine Arbeitsgruppe, die die Probleme, die bei der Kalibrierung mit PD Kalibrierstandards entstehen und in erster Linie durch klimatische Einflüsse verursacht werden, untersuchen sollte. Die Ergebnisse der Arbeitsgruppe führte zu einer Harmonisierung der Kalibriermethoden zwischen den Labors der Zulieferer und einer Methode zur Kompensation der Einflüsse klimatischer Umgebungsbedingungen. Insgesamt wurden die laborabhängigen Unterschiede beträchtlich reduziert, so dass es unter Umständen zu einer Überarbeitung der von der CORESTA empfohlenen Methode und der ISO-Norm 6565 kommen wird. Während der Tätigkeit der Arbeitsgruppe wurde offensichtlich, dass weitere Arbeiten nötig sein werden, um ähnliche Fehler, die während der Kalibrierung des PD Messinstrumentes und den PD Messungen von Zigaretten- und Filterstabproben auftreten, zu eliminieren. Diese Fehler treten in alläglichen Messsituationen aufgrund von Schwierigkeiten beim Erreichen der klimatischen Vorgaben der ISO 6565 und von anderen notwendigen Anforderungen auf. Dies kann Fehler beim angegeben Druckabfall (PD) zur Folge haben und das Vertrauen in die Ergebnisse erheblich herabsetzen. Dieses Dokument behandelt einige der praktischen Probleme bei der Messung des PD und versucht den Fehlertyp und das mögliche Fehlerausmaß abzuschätzen. [Beitr. Tabakforsch. Int. 22 (2006) 6-12] 


\section{RESUME}

La méthode de mesure de la résistance au tirage d'un bâtonnet filtre et d'une cigarette est définie dans la norme ISO 6565-2002 (1). Cette norme définie l'étalonnage et l'utilisation d'étalons de transferts pour la calibration des instruments de mesure, et définie également la procédure de mesure sur des échantillons de filtres et de cigarettes. La procédure décrite dans la norme suppose que les conditions de mesure sont constantes et que l'échantillon est à l'équilibre avec son environnement.

En 2001, le Centre de Coopération pour les Recherches Scientifiques Relatives au Tabac (CORESTA) a créé une équipe de travail (Task Force) pour étudier les problèmes associés à la calibration des étalons de transfert, qui sont liés, en premier lieu, aux effets des conditions ambiantes. Le travail de cette équipe de travail a conduit à l'alignement des méthodes d'étalonnage des fournisseurs et à une méthode de compensation des effets des conditions atmosphériques. Ceci a eu pour conséquence de réduire considérablement les écarts inter laboratoires et conduira éventuellement à une révision de la méthode recommandée du CORESTA et de la norme ISO 6565.

Durant les essais de cette équipe de travail, il est apparu comme évident de poursuivre les travaux sur d'autres sources d'erreurs similaires, liées aux processus de calibration des instruments et de mesures sur filtre et cigarette. Ces erreurs apparaissent dans des conditions réelles de mesure liées aux difficultés de correspondre à l'ISO 6565 et de satisfaire à d'autres exigences. Ceci peut augmenter les erreurs de mesures de perte de charge et peut fortement réduire la confiance dans les résultats.

Cet article analyse plusieurs problèmes pratiques pouvant se présenter dans la mesure de la résistance au tirage, et tente d'estimer le type et l'amplitude des erreurs qui pourraient apparaître. [Beitr. Tabakforsch. Int. 22 (2006) 6-12]

\section{SOMEFACTORS THATCAN AFFECT THE ACCURACY OF PRESSURE DROP MEASUREMENTS}

\section{The calibration of pressure drop transfer standards}

International Standard (ISO) 6565-2002 defines the calibration and use of a transfer standard to calibrate the pressure drop (PD) measuring instrument. As the measured value depends upon the ambient conditions, the transfer standard is calibrated under industry standard atmospheric conditions of $22{ }^{\circ} \mathrm{C}, 60 \%$ relative humidity (RH), 1013 mbar as defined in ISO 3402.

The work carried out over the last two years by the Task Force on Pressure Drop Calibration established by the Cooperation Center for Scientific Research Relative to Tobacco (CORESTA), was reported at the 2003 meeting of the CORESTA Smoke Science and Product Technology Groups, held in Freiburg. This Task Force has evaluated the effects of ambient temperature, pressure and humidity on the measured value of a PD standard and has developed a method for the compensation of the marked value of PD calibration standards when they are calibrated under non-standard conditions. This work showed, amongst other things, that PD standards are not completely linear but exhibit a small degree of non-linearity or turbulent airflow. At an airflow of $17.5 \mathrm{~mL} / \mathrm{s}$, between $4 \%$ and $8 \%$ of the total PD is due to non-linear effects (dependant upon the PD of the standard) making the measured PD susceptible to changes in atmospheric pressure (2). This may also mean that additional compensation needs be applied when these standards are used to calibrate pressure drop measuring instruments.

\section{The calibration of pressure drop measurement instruments}

ISO 6565 further defines that the transfer standard, calibrated as previously described, is used to calibrate the PD measuring instrument under the ambient conditions that exist at the measurement location. This is achieved by allowing the calibration standard to reach equilibrium with the measurement environment and then applying the calibration. In this way, the instrument is forced to indicate the PD marked on the calibration standard, i.e. the value established for standard during its calibration.

The measuring instrument has thus been "scaled" to indicate the PD values that would exist for the measured samples under standard atmospheric conditions. If, however, the environmental conditions change significantly, the calibration becomes invalid and the instrument must be recalibrated. The extent of the calibration error will depend upon the amount by which the atmospheric conditions have changed since the instrument was calibrated.

\section{The measurement of samples}

During the subsequent PD measurements made on samples, ISO 6565 requires that the test environmental conditions are constant and identical to those under which the instrument calibration was made. It also assumes that the test piece is in equilibrium with both the PD measuring instrument and the environment at the point of measurement. Under these conditions

1) the measurement air flowrate and its humidity and temperature (and hence its viscosity and density) will be identical to those at the time of instrument calibration;

2) there will be no changes to the temperature and humidity of the measurement air as it passes through the sample and the instrument.

If these conditions are not met, there are two potential areas for error:

Firstly, when the atmospheric conditions at the time of measurement are different to those at the time of instrument calibration, there will be errors in the measured PD of the sample caused by changes in the measurement air. These errors are mainly due to changes in the air viscosity and volumetric flow rate through the measured sample (2). Recognising this, ISO 6565 requires recalibration of the instrument if the atmospheric conditions change by more than $2{ }^{\circ} \mathrm{C}$ or $5 \% \mathrm{RH}$. In practice, recalibration usually takes place no more frequently than once per manufacturing shift, which may not comply with the ISO 6565 requirement. In addition, if the sample has any significant degree of nonlinearity, there may also be error contributions due to changes in air density caused by changes in atmospheric pressure (2). This error is not mentioned in ISO 6565 but can lead to an additional error if not corrected. 
Table 1. The effects of environmental conditions on PD of multi-capillary calibration standards, as determined by the CORESTA Pressure Drop Calibration Task Force

\begin{tabular}{l|l}
\hline Parameter & Measured effect \\
\hline Temperature & $0.23 \% /{ }^{\circ} \mathrm{C}$ change in air temperature \\
Humidity & $0.03 \% / 10 \% \mathrm{RH}$ change in air moisture \\
Atmospheric pressure & $0.27 \% / 50 \mathrm{mbar}$ change in atmospheric pressure (at $400 \mathrm{mmWG})$ \\
& $0.41 \% / 50 \mathrm{mbar}$ change in atmospheric pressure (at $800 \mathrm{mmWG})$ \\
\hline
\end{tabular}

Secondly, when the cigarette or filter rod sample is not in equilibrium with the measurement air or the environment it will cause changes to the measurement air flowing through it and hence modify the measurement conditions. This will cause changes in the air flowrate and viscosity of the air flowing through the sample. These changes, being short term, are due mainly to changes in the sample moisture and temperature.

This situation can occur, for example, when samples are taken directly from the output of a manufacturing machine and measured without a sufficient period of time for equilibrium to occur. This is the normal situation in most manufacturing departments. If automatic sampling is used, the situation can be made more acute - on the one hand the sample is brought to the measurement very soon after manufacture, with little opportunity to reach equilibrium with the environment and secondly, if compressed air is used to transport the sample, this may cause changes to the sample moisture and temperature that can further influence the measurement.

\section{Considerations of sleeve size and sample hardness}

ISO 6565 requires that filter rods are fully encapsulated in an impermeable sleeve during the measurement of PD. This sleeve can have an effect on the measured PD, particularly if its diameter is not critically matched to that of the sample under test. If the inner diameter of the sleeve is too large, air will leak past the rods and cause the measured PD to be low. If the inner diameter of the sleeve is too small, there may be some compression of the sample, reducing its diameter and hence increasing the measured PD. This latter situation is obviously also affected by the firmness or hardness of the sample under test - firmer samples being less susceptible to compression.

\section{ESTIMATION OF THE MAGNITUDE OF THE ERRORS}

\section{Calibration errors due to changes in environmental conditions after calibration}

The effects of environmental conditions on the PD of a multi-capillary calibration standard have been estimated from measurements on actual standards (2) and are summarised in Table 1.

\section{Calibration errors due to non-equilibrium of calibration standard}

A further error will be introduced if the calibration standard is not in thermal equilibrium with the measurement air at the time of calibration. This can occur, for example, due to handling of the PD standard during calibration. Measurements of the temperature of a PD standard show a temperature rise of about $1.5^{\circ} \mathrm{C}$ when the standard is held for $10 \mathrm{~s}$ (this time was chosen as the typical time taken to transfer a standard from storage container to the PD extension tube). Hence, before calibrating a PD measurement instrument, ISO 6565 requires that the calibration standard should be brought into equilibrium with the measurement air by allowing the air to flow through it until no further change in PD occurs. This can take from 3 to 5 min under normal conditions.

\section{Errors due to non-equilibrium of the sample under test}

The effect of moisture and air humidity: This effect was estimated by carrying out two sets of measurements on a single filter rod sample (Figure 1). The sample was firstly brought into equilibrium over $48 \mathrm{~h}$ with the measurement environment $\left(22{ }^{\circ} \mathrm{C}, 60 \% \mathrm{RH}\right)$. The sample was then measured continuously for several minutes in a pressure induced PD instrument (in this case a Cerulean Quality Test Module, type QTM6P). The sample was then immediately transferred to a vacuum induced PD instrument (a Cerulean Quality Test Module, type QTM6V) for a similar period. This behaviour can be explained by considering the initial moisture content of the measurement air and the sample. The sample was initially in equilibrium with the environment $\left(22^{\circ} \mathrm{C}, 60 \% \mathrm{RH}\right)$. The QTM6P has a pressure derived flow generator and the measurement air is derived from a compressed air source. This air is passed through a filter regulator device that not only stabilises the pressure but removes almost all of the remaining moisture. Hence the measurement air has virtually no moisture $(\mathrm{RH}<5 \%)$ and, when the filter sample is measured in the QTM6P, it is being dried out by the measurement airflow and hence it is subjected to cooling which causes the measured PD to fall sharply until the moisture content of the sample has been reduced to that of the air. The sample then slowly returns to the same temperature as the measurement air and in so doing the measured PD returns to its initial value.

When transferred to the vacuum based instrument (QTM6V), the initially dry sample is measured using air at $60 \% \mathrm{RH}$ (i.e. that of the measurement environment) and hence it immediately begins absorbing moisture from the air and hence undergoes heating which causes the measured PD to rise sharply. Once the sample has returned to equilibrium with the measurement air, its measured PD returns to its initial value.

In order to estimate the potential error due to non-equilibrium of moisture the initial slope values have been used to derive the PD shift over a six second measurement time. 


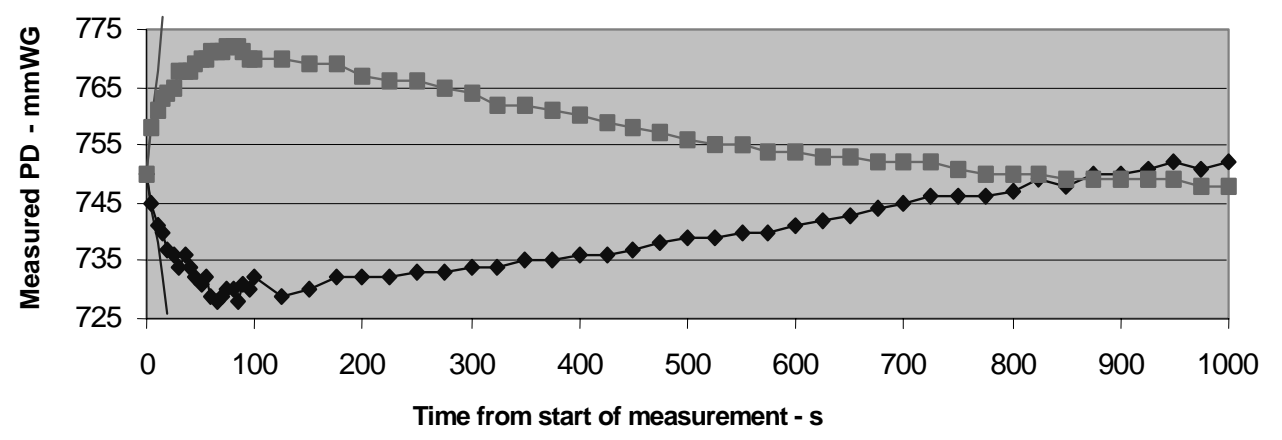

$\longrightarrow$ PD - QTM6P - Run 1
- Initial slope, run $1=-1.2 \mathrm{mmWG} / \mathrm{s} \longrightarrow$ Initial slope , run $2=1.8 \mathrm{mmWG} / \mathrm{s}$

Figure 1. Behaviour of $750 \mathrm{mmWG}$ filter rod measured first in QTM6P and then in QTM6V to demonstrate the effects of moisture gain and loss

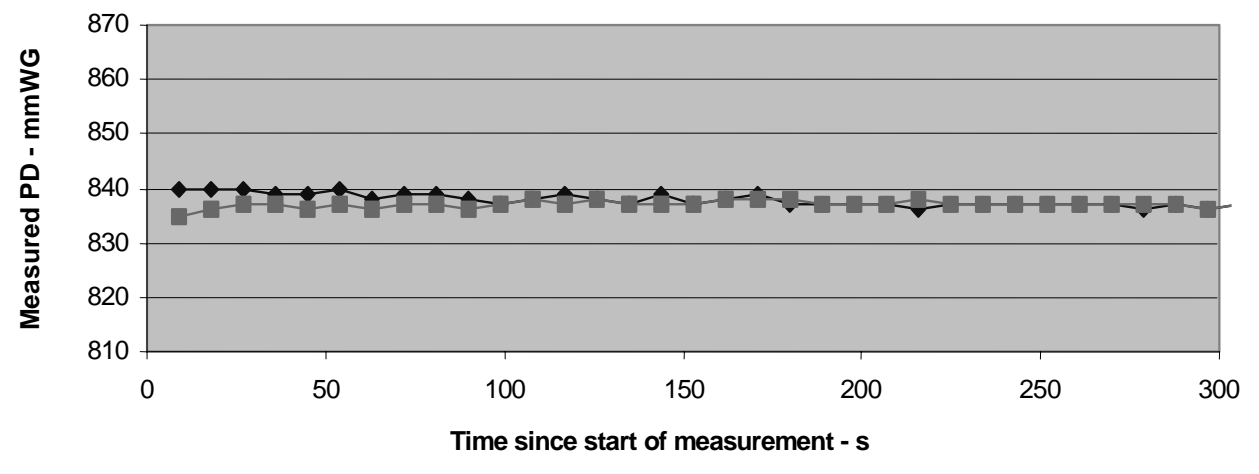

$\rightarrow$ Calibration Standard - QTM6P $\rightarrow$ - Calibration Standard - QTM6V

Figure 2. PD of multi-capillary calibration standard measured first in QTM6P and then QTM6V

This is estimated at $0.5 \%$ of the initial value for a $20 \%$ difference in moisture level and $1.5 \%$ for a $60 \%$ difference (e.g. using pressure based PD instrument).

This behaviour can be confirmed as being due to moisture by making the same measurements on a multi-capillary PD standard (Figure 2). Here, the moisture content of the standard is zero throughout the measurements and hence no change in measured PD takes place because of this.

Effect of temperature: A filter rod was initially conditioned to 22 degrees Celsius. The conditioned sample was then measured in a vacuum based PD instrument, in an environment at 30 degrees Celsius. The temperature of the filter rod during this measurement was measured by embedding a low mass thermocouple into the filter rod. The initial rate of temperature change is estimated as $0.13{ }^{\circ} \mathrm{C}$ per second by estimating the initial slope of the Temperature / Time curve (Figure 3 ).
A second, similar measurement (Figure 4) was carried out to estimate the effect of this temperature change on the measured PD of the filter. In this case, the filter rod temperature was measured using a foil thermocouple wrapped round the filter rod, so as not to disturb the flow. Here, a change of 9.3 degrees produces a change of $8.8 \mathrm{mmWG}$ or $0.22 \%$ per degree Celsius. This figure is in close agreement with the value of $0.23 \%$, obtained for a multi-capillary standard by the CORESTA Task Force (2).

From these two measurements, the effects of temperature difference over a six second measurement time are estimated at $0.18 \%$. This equates to $1.5 \mathrm{mmWG}$ on an $800 \mathrm{mmWG}$ filter rod.

\section{Effects of sleeve size}

The PD of a number of fully cured, wrapped acetate filter rods of conventional design was measured in latex sleeves 


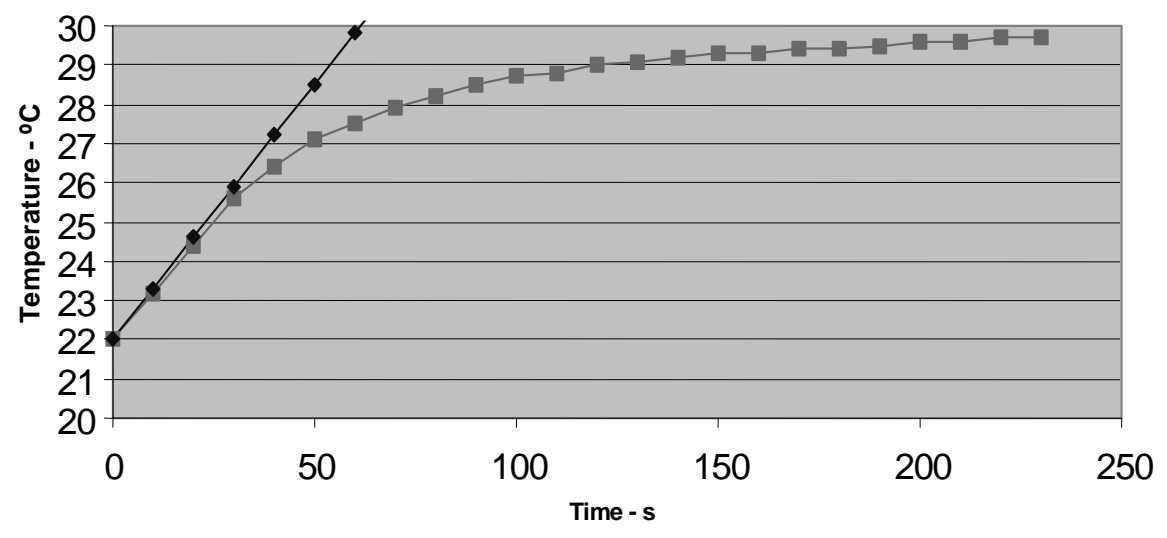

Temperature $\longrightarrow$ Initial slope $=0.13^{\circ} \mathrm{C} / \mathrm{s}$

Figure 3. Temperature change for a filter rod during non-isothermal measurement

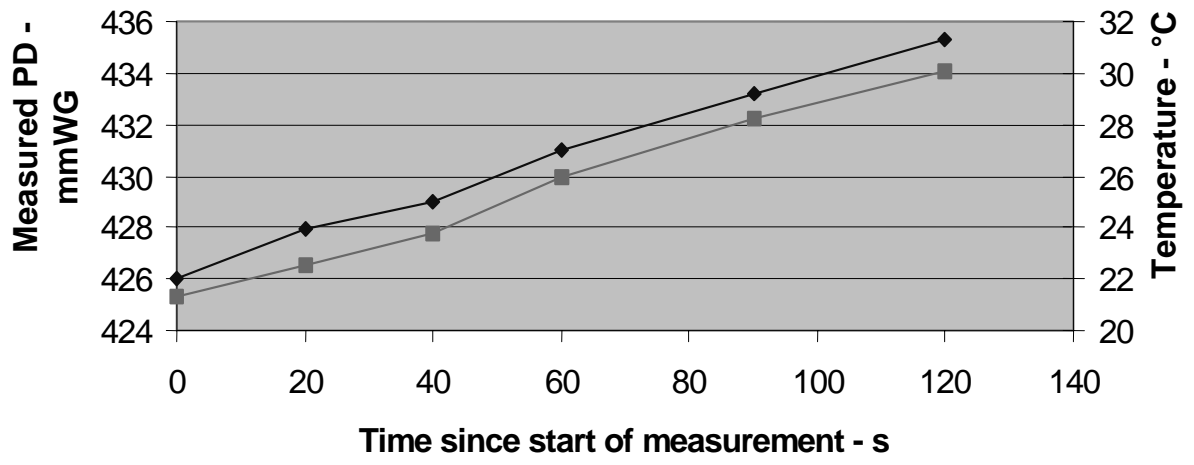

$\rightarrow$ PD $\multimap$ Temperature

Figure 4. Temperature and PD change for a filter rod during non-isothermal measurement

Table 2. Normalised PD vs. sleeve diameter for various sizes of cured, wrapped acetate filter rod

\begin{tabular}{l|c|c|c|c|c|c|c}
\hline \multirow{2}{*}{$\begin{array}{l}\text { Nominal rod } \\
\text { diameter, } \mathrm{mm}\end{array}$} & \multicolumn{7}{c}{ Inside diameter of sleeve, $\mathrm{mm}$} \\
\cline { 2 - 8 } & 5.0 & 5.5 & 6.0 & 6.5 & 7.0 & 7.4 & 8.0 \\
\hline 5.63 & 1.000 & 0.995 & 0.982 & - & - & - & - \\
6.04 & 1.002 & 1.001 & 1.002 & - & - & - & - \\
6.7 & 1.010 & 1.008 & 1.000 & 0.997 & 0.940 & - & - \\
7.06 & 1.025 & 1.017 & 1.002 & 1.002 & 0.965 & 0.928 & - \\
7.60 & - & 1.019 & 1.015 & 1.007 & 1.002 & 1.002 & - \\
7.67 & - & 1.025 & 1.020 & 1.013 & 1.002 & 1.003 & 0.885 \\
8.66 & - & 1.013 & 1.011 & 1.012 & 1.002 & 1.002 & 1.001 \\
\hline
\end{tabular}

of varying inside diameter. The sleeves were manufactured from cured natural latex and were $0.35 \mathrm{~mm}$ wall thickness. The measured PD was normalised to the value obtained using a sleeve of inside diameter of equal to between $90 \%$ and $98 \%$ the nominal sample diameter and the results are given in Table 2. Each data point in the table is the mean of at least five determinations and each determination is the mean measured PD of a batch of five filter rods.

In the table, a dash has been entered where it was impossible to measure the sample (due to the sleeve being too small or too big) or where the measured PD was below $70 \%$ of the nominal value, due to leakage round the sample. For comparison purposes, a range of nominal PD $\pm 1 \%$ was taken as being acceptable and any value falling outside this range is shown in the table in italic type.

These experiments confirmed that, if the measured PD is to be maintained within $1 \%$ of the nominal value, then the sleeve needs to be closely matched to the rod size. Although there are seen to be some differences in the results for different rod and sleeve combinations, the graphs allow a reasonable 


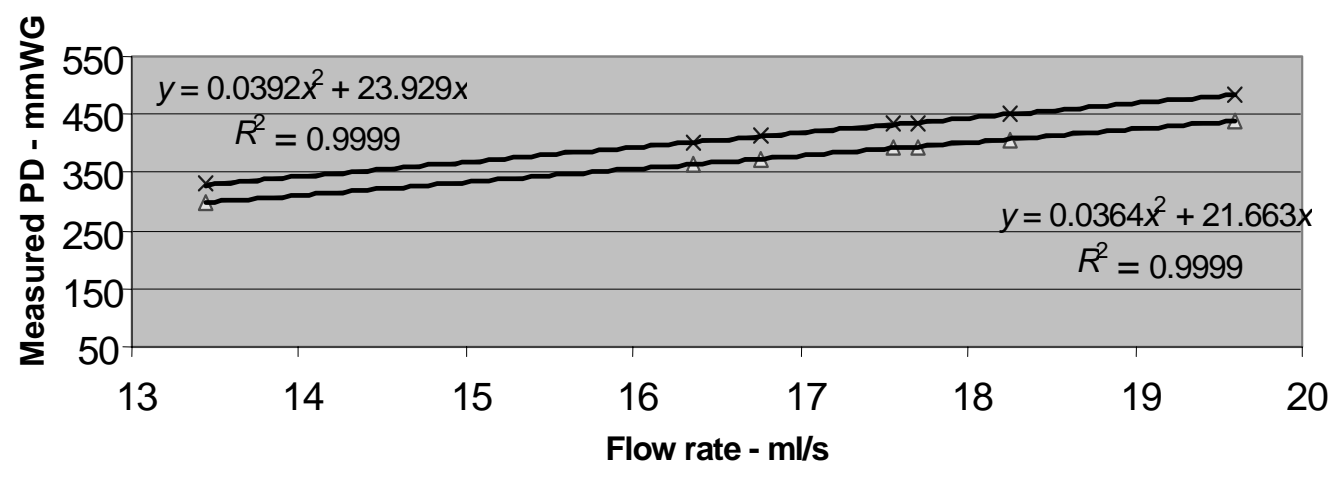

$$
\begin{aligned}
& -\triangle 392 \mathrm{mmWG} \text { Std. } \quad \longrightarrow 420 \mathrm{~mm} \text { wrapped acetate } \\
& \square \text { Poly.(420 mm wrapped acetate) } \longleftarrow \text { Poly. (392 mmWG Std.) }
\end{aligned}
$$

Figure 5. Measured PD of a $392 \mathrm{mmWG}$ PD standard and $420 \mathrm{mmWG}$ wrapped acetate filter rod at different flow rates

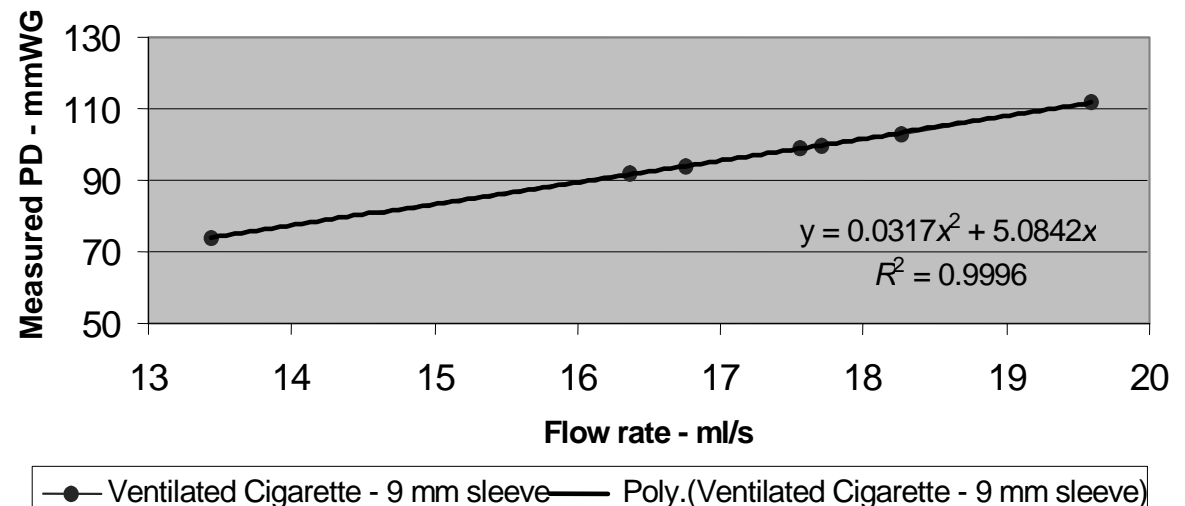

Figure 6. Measured PD of a ventilated cigarette at different flow rates

estimation of the acceptable working range to be made for cured filter rods. Here, a sleeve of internal diameter $D$ can safely be used with rods in the size range $D+0.1 \mathrm{~mm}$ to $D+$ $1.0 \mathrm{~mm}$ and in some cases for rods in excess of $D+1.5 \mathrm{~mm}$. Uncured filter rods, such as those taken directly from the filter making machine, will be somewhat softer and hence a lower limit must be used for the maximum rod size that may be measured in a particular size of sleeve, to avoid the sample being crushed by the sleeve. It is very difficult to estimate this range by direct measurement because the rod hardness is changing continuously throughout the first few hours after manufacture due to the curing of the plasticiser.

\section{Investigation into non-linear effects}

A series of PD measurements of different types of cigarette, filter and PD standard were made over a range of measurement airflows (Figure 5 and Figure 6). The measurements were made using a vacuum induced PD instrument with flow controlled by a Critical Flow Orifice (CFO). The instrument was specially adapted to allow one of seven different CFO devices to be switched into circuit, thus allowing the flow to be readily modified. (The actual flow rate of each CFO had been previously determined.) The instrument was located in an area whose environment was closely controlled in accordance with ISO 3402. the instrument was calibrated according to ISO 6565 at $17.5 \mathrm{~mL} / \mathrm{s}$ prior to the measurements.

These measurements show that all the samples investigated have some degree of non-linearity. This can be assessed by evaluating the contribution of the flow-squared term to the total PD measured at $17.5 \mathrm{~mL} / \mathrm{s}$ airflow, as follows:
- 392 mmWG multi-capillary standard $2.8 \%$
- $420 \mathrm{mmWG}$ wrapped acetate filter rod $2.8 \%$
- $50 \%$ filter ventilated cigarette $\quad 9.8 \%$

This non-linear behaviour will become important if there are significant changes in atmospheric pressure subsequent to the instrument being calibrated. The magnitude of the PD change for a filter rod due to atmospheric pressure changes will be similar to that for the calibration standard (i.e. $0.41 \%$ per 50 mbar change). For a cigarette, the change would be considerably higher at about $1.5 \%$ per 50 mbar change in atmospheric pressure. However, this non-linear component for the cigarette, whilst larger in percentage terms, is unlikely to make the change more significant in terms of cigarette smoking performance, due to the lower PD (draw resistance) of cigarettes compared to filters. 
Non-linearity will also have some effect on the measured PD value if the measurement airflow is different from the standard $17.5 \mathrm{~mL} / \mathrm{s}$. In this case, the linear compensation provided by the present instrument calibration process will produce a slight error due to the non-linear component of the sample PD. For example, a filter rod of $430 \mathrm{mmWG}$ nominal $\mathrm{PD}$ (at $17.5 \mathrm{~mL} / \mathrm{s}$ ), when measured at $16 \mathrm{~mL} / \mathrm{s}$, will produce a PD of $429 \mathrm{mmWG}$ (i.e. $0.25 \%$ error). A ventilated cigarette of $100 \mathrm{mmWG}$ draw resistance would measure 99.15 mmWG under similar conditions (i.e. $0.85 \%$ error).

\section{CONCLUSIONS}

The work started by the CORESTA Task Force on Pressure Drop Calibration has considerably improved the precision and accuracy of calibration of multi-capillary glass PD standards. However, material suppliers and filter manufacturers are now seeking PD measurement accuracies of $1 \%$ or better. This paper has attempted to highlight the major errors that can occur during PD measurement and to quantify their magnitude. Since completing this experimental work, CORESTA convened a sub group in May 2005 to monitor and maintain physical test methods. This group will carry out further work on these and other issues associated and will make recommendations for any possible upgrade to ISO 6565.

\section{REFERENCES}

1. ISO 6565:2002: Tobacco and tobacco products - Draw resistance of cigarettes and pressure drop of filter rods - Standard conditions and measurement; International Organization for Standardization, Geneva, Switzerland, 2002.

2. Colard, S., W. Trinkies, G. Cholet, B. Camm, M. Austin, and R. Gualandris: Compensation for ambient conditions effects on multi-capillary pressure drop standards calibration; Presented at Coresta Joint Smoke Science and Product Technology Group Meeting, Paper No. ST03, Freiburg, September 2003.

Corresponding author:

Malcolm Austin

CERULEAN

Rockingham Drive

Linford Wood East

Milton Keynes, MK14 6LY

UK

E-mail:Malcom.Austin@cerulean.com 